\title{
Distribution of vascular endothelial growth factor (VEGF) and its binding sites at the maternal-fetal interface during gestation in pigs
}

\author{
D. S. Charnock-Jones ${ }^{1}$, D. E. Clark ${ }^{1}$, D. Licence ${ }^{1}$, K. Day $^{1}$, \\ F. B. P. Wooding ${ }^{2}$ and S. K. Smith ${ }^{1}$ \\ ${ }^{1}$ Reproductive Molecular Research Group, Department of Obstetrics \& Gynaecology, \\ University of Cambridge, The Rosie Hospital, Cambridge CB2 2SW, UK; \\ and $^{2}$ The Babraham Institute, Babraham, Cambridge CB2 4AQ, UK
}

Pigs show epitheliochorial placentation, in which the maternal uterine epithelium and the fetal trophectoderm become closely apposed. There is no invasion of trophoblast into the maternal tissue, and nutrient and waste exchange take place across two epithelial layers beneath which a complex network of capillaries forms. Later in gestation, the epithelial cells become indented by blood vessels, which greatly reduces the distance for diffusion between the two circulatory systems. Vascular endothelial growth factor is a secreted homodimeric angiogenic growth factor that is involved in physiological and pathological angiogenesis. Its receptors are generally restricted to endothelial cells. Ligand binding, in situ hybridization and immunohistochemistry were carried out in pig placenta throughout gestation to investigate the possible role of vascular endothelial growth factor and its receptors in non-invasive placentation. In situ hybridization and immunohistochemistry revealed that mRNA and immunoreactivity for vascular endothelial growth factor were localized in both maternal and fetal epithelial cells at the maternal-fetal interface and over the maternal glands, although the signal was generally weaker in the maternal glands. Ligand binding was used to localize for vascular endothelial growth factor receptors; no binding was observed over the maternal glands, but very strong binding was localized to the endometrial blood vessels. At the interface between maternal and fetal tissue, a similar pattern was observed whereby the numerous small capillaries at the bases of the two apposed epithelia bound vascular endothelial growth factor specifically. It is concluded that vascular endothelial growth factor produced by the maternal and fetal epithelial layers promotes the growth of capillaries locally, which would facilitate the development of two vascular networks for the efficient transfer of nutrients and waste products.

\section{Introduction}

Comparative biology has revealed many similarities among disparate groups of mammals. However, this type of study has also revealed marked variation in placental architecture between even closely related groups (for a review, see Wooding and Flint, 1994). Humans and pigs show haemochorial and epitheliochorial placentation, respectively, which represent two extremes in the range of placental structures seen in mammals. Despite the marked differences, the underlying purpose of both types of placenta is to facilitate an increasing amount of exchange between maternal and fetal circulations. For the exchange to occur, both circulations need to proliferate simultaneously and be brought into close apposition. Thus, in all types of placenta there is marked growth of blood vessels, which is regulated carefully, ensuring that the correct vessel architecture develops to enable maximum exchange.

The control of blood vessel growth in a variety of physiological and pathological situations is achieved by the

Email: dscj1@cam.ac.uk delicate balance between positive and negative effectors (Hanahan and Folkman, 1996). One of the most potent stimulators of angiogenesis is vascular endothelial growth factor (VEGF). VEGF is a homodimeric glycoprotein of which there are five alternatively spliced forms containing $121,145,165,189$ or 206 amino acids in each of the monomers (Houck et al., 1991; Charnock-Jones et al., 1993). VEGF plays an important role in pathological angiogenesis in a variety of tissues, for example in the eye (Alon et al., 1995) and in a variety of solid tumours (Berse et al., 1992). It is also important in physiological angiogenesis, for example in the endometrium (Charnock-Jones et al., 1993; Torry et al., 1996), the ovary (Philips et al., 1990) and the embryo (Jakeman et al., 1993). Knockout studies have shown that mice carrying a single disrupted allele for this gene die at between day 11 and day 12 of embryonic development (Carmeliet et al., 1996; Ferrara et al., 1996).

Other studies (Sharkey et al., 1993; Charnock-Jones et al., 1994; Jackson et al., 1994; Shiraishi et al., 1996) have shown that VEGF is highly expressed in the human decidua and placenta. The main sites of VEGF expression are within the maternal and fetal macrophages, although expression in 
placental fibroblasts and trophoblast has also been reported (Sharkey et al., 1993; Anthony et al., 1994; Charnock-Jones et al., 1994). Furthermore, in situ hybridization revealed that the villous (but in particular, the extravillous) trophoblast within the human placenta contains abundant mRNA encoding one of the VEGF receptors (flt) (Charnock-Jones et al., 1994; Clark et al., 1996). Thus, it is possible that VEGF has direct actions on some types of trophoblast.

This study investigated the possible role of VEGF in trophoblast migration, in contrast to its direct effects on blood vessel growth, by determining the distribution of cells capable of producing VEGF, and also of those cells capable of responding to the growth factors, in the pig placenta, in which there is no trophoblast invasion of maternal tissue.

\section{Materials and Methods}

\section{Materials}

Radioisotopes, [ ${ }^{33}$ P]UTP and ${ }^{125}$ I-labelled VEGF, were obtained from Amersham International Plc (Amersham). Unlabelled VEGF was obtained from R\&D Systems (Abington). Anti-VEGF antibody was a polyclonal antiserum raised against the $\mathrm{N}$-terminus of human VEGF and was supplied by Santa Cruz Biotechnology (Wembley). MIL-11, a monoclonal antibody specific for endothelial cells, was obtained from M. Bailey and C. Stokes, University of Bristol. Other immunohistochemical reagents were obtained from vector (Peterborough).

\section{Animals}

Large White pigs (at defined days after mating) from the herd at the Babraham Institute were used. Animals were maintained and used in accordance with local and national regulations.

\section{Tissue}

Tissue was collected from nine pregnant pigs, and at all stages of gestation the multiple conceptuses were sampled in different ways. Embryonic tissue and membranes were recovered from the uterine cavity by flushing with TCM as described by Gadsby et al. (1980). For ligand binding (days 24, 51, 92 and 108 after mating), placental tissue was dissected from the myometrium and several blocks of tissue were cooled gradually in liquid nitrogen before storage at $-70^{\circ} \mathrm{C}$. In addition, tissue for immunohistochemistry and in situ hybridization was fixed in formalin $(4 \%(\mathrm{v} / \mathrm{v})$ formaldehyde at room temperature for 6-8 h) and embedded in paraffin wax. For optimal preservation of the maternofetal apposition, at some time points (days 16, 18, 22, 25, 51, 100 and 108 after mating), individual conceptuses were fixed by cannulation and perfusion of the local uterine (and occasionally fetal) vasculature with 4\% (v/v) formaldehyde or $1 \%$ (v/v) glutaraldehyde, and embedded in paraffin wax.

\section{RT-PCR}

RNA was prepared from tissues obtained at days 18, 22, 51 and 108 after mating using methods described by Charnock-Jones et al. (1993). First strand cDNA was synthesized using an oligo-dT primer and AMV reverse transcriptase (Super-RT; HT Biotec, Cambridge). Amplification was carried out in two stages using a touch-down protocol. The first round amplification used primers CABG and PV2 (5' CGGAATTCCATGAACTTTCTGCTGTCT 3' and 5' TCACCGCCTCGGCTTTC 3', respectively) and the following cycles: $\left(95^{\circ} \mathrm{C}\right.$ for $30 \mathrm{~s}, 72^{\circ} \mathrm{C}$ for $\left.60 \mathrm{~s}\right) \times 5$; $\left(95^{\circ} \mathrm{C}\right.$ for $30 \mathrm{~s}, 58^{\circ} \mathrm{C}$ for $30 \mathrm{~s}, 72^{\circ} \mathrm{C}$ for $\left.30 \mathrm{~s}\right) \times 25$. A proportion of these reaction products $(1 \mu \mathrm{l})$ was transferred to the second round reaction and amplified using primers PV1 (5' TGTGAATGCAGACCAAAG $3^{\prime}$ ) and PV2, and the following cycles: $\left(95^{\circ} \mathrm{C}\right.$ for $30 \mathrm{~s} ; x^{\circ} \mathrm{C}$ for $\left.60 \mathrm{~s}\right) \times 2$, where $x$ is 58,56 , 54 and 52 ; $\left(95^{\circ} \mathrm{C}\right.$ for $30 \mathrm{~s}, 50^{\circ} \mathrm{C}$ for $30 \mathrm{~s}, 72^{\circ} \mathrm{C}$ for $\left.30 \mathrm{~s}\right) \times 25$. Each reaction tube contained $50.0 \mu \mathrm{l}$ of $10.0 \mathrm{mmol}$ Tris-Cl I-1, pH 8.3, $50.0 \mathrm{mmol} \mathrm{KCl} \mathrm{I-1,} 1.5 \mathrm{mmol} \mathrm{MgCl}_{2} \mathrm{I}^{-1}$, $200.0 \mu \mathrm{mol}$ dNTPs $\mathrm{I}^{-1}, 0.3 \mu \mathrm{mol} \mathrm{I}^{-1}$ of each primer and 25 $\mathrm{U}$ taq polymerase $\mathrm{ml}^{-1}$. Products were analysed by agarose gel electrophoresis. A negative control (no added template) was amplified at the same time.

\section{In situ hybridization}

The procedure used for in situ hybridization was based on that described by Clark et al. (1996) using material fixed in formaldehyde and embedded in paraffin wax. The probe used in this study was a fragment of the human VEGF CDNA (bases 57-446; Leung et al., 1989) from which both sense and antisense ${ }^{33} \mathrm{P}$-labelled transcripts were generated in vitro. This probe was chosen because it has minimal crossreactivity with placenta growth factor (PIGF), but is sufficiently conserved to work in non-human species. After hybridization and washing, the sections were exposed to autoradiographic emulsion for 2-3 weeks. After development, these sections were stained and photographed as described above for the ligand binding experiments.

\section{Immunocytochemistry}

Localization of VEGF-like immunoreactivity was performed as described by Clark et al. (1996) using a polyclonal anti-VEGF antibody (A-20 Santa Cruz Biotechnology) on material fixed in formaldehyde and embedded in paraffin wax. Control sections were stained either with the primary antibody replaced with an equal concentration of non-immune rabbit serum or with antibody that had been pre-adsorbed with a 25-fold molar excess of the peptide used to immunize the animal (Santa Cruz Biotechnology). Blood vessels were localized using MIL-11, a monoclonal antibody specific for endothelial cells. MIL-11 was used on acetone-fixed frozen sections with silver enhanced immunogold localization. 


\section{I-labelled VEGF binding}

Sections of unfixed frozen tissue were obtained and [125I]-VEGF binding was carried out according to the method described by Shweiki et al. (1993). In brief, sections were pre-incubated in PBS containing $0.2 \%(\mathrm{w} / \mathrm{v})$ gelatine and $1 \mathrm{mg}$ heparin $\mathrm{ml}^{-1}$ for $30 \mathrm{~min}$ at room temperature. ${ }^{125 \mathrm{I}}$ labelled VEGF (Amersham International; $1500 \mathrm{Ci} \mathrm{mmol}^{-1}$ ) was added to the same buffer to a final concentration of 100 pmol $\mathrm{I}^{-1}$. A control serial section containing excess unlabelled VEGF $\left(3 \mathrm{nmol} \mathrm{I}^{-1}\right.$ ) was processed in parallel. Both control and experimental sections were incubated for $1 \mathrm{~h}$ at room temperature after which they were washed in cold PBS, fixed in 2.5\% (v/v) glutaraldehyde and washed again. After the slides were air dried, they were dipped in autoradiographic emulsion (LM1 emulsion, Amersham International) and developed after $48 \mathrm{~h}$. Once developed and counterstained with haematoxylin, the sections were photographed under both bright field and dark field illumination using a Leica DMRB/E microscope. Some sections were analysed using both ligand binding and immunohistochemistry. In these cases, ligand binding was performed first, but the sections were not exposed to autoradiographic emulsion. Subsequently, immunohistochemistry was carried out using an anti-cytokeratin monoclonal antibody (Dako MNF116). The detection system used was $A B C$ horseradish peroxidase (Vector) and diaminobenzidine (DAB). Finally, the slides were dipped in emulsion and exposed as described earlier.

\section{Results}

\section{$R T-P C R$}

PCR analysis of cDNA derived from RNA obtained at several stages of gestation showed that three specific products were produced (Fig. 1). The primers used for the second round amplification flank the alternatively spliced region of the VEGF-A gene. The sizes of the products produced at this stage are consistent with the known splicing pattern of VEGF-A (63, 195 and 267 base pairs for VEGF-A ${ }_{120}$, VEGF-A 164 and VEGF-A 188 , respectively).

\section{VEGF immunohistochemistry and in situ hybridization}

Tissue samples collected at various stages of gestation were analysed using a specific antiserum raised against the $\mathrm{N}$-terminus of VEGF and a cRNA probe to detect the specific mRNAs encoding VEGF, to identify expression sites of VEGF in pig placentae. Some of this tissue (for example, at day 51 after mating and at day 108 after mating; Fig. $2 \mathrm{~d}-\mathrm{g}$ ) was fixed by perfusion. The specimens and tissue fixed by immersion were then embedded in paraffin wax.

VEGF-like immunoreactivity was located consistently in the epithelial cells, including the glandular epithelium (Fig. $2 a, b)$, but also in the opposing fetal trophoblast and maternal-epithelial interface (Fig. 2d-f). Scattered cells within the fetal tissue stained strongly for VEGF (Fig. 2f).

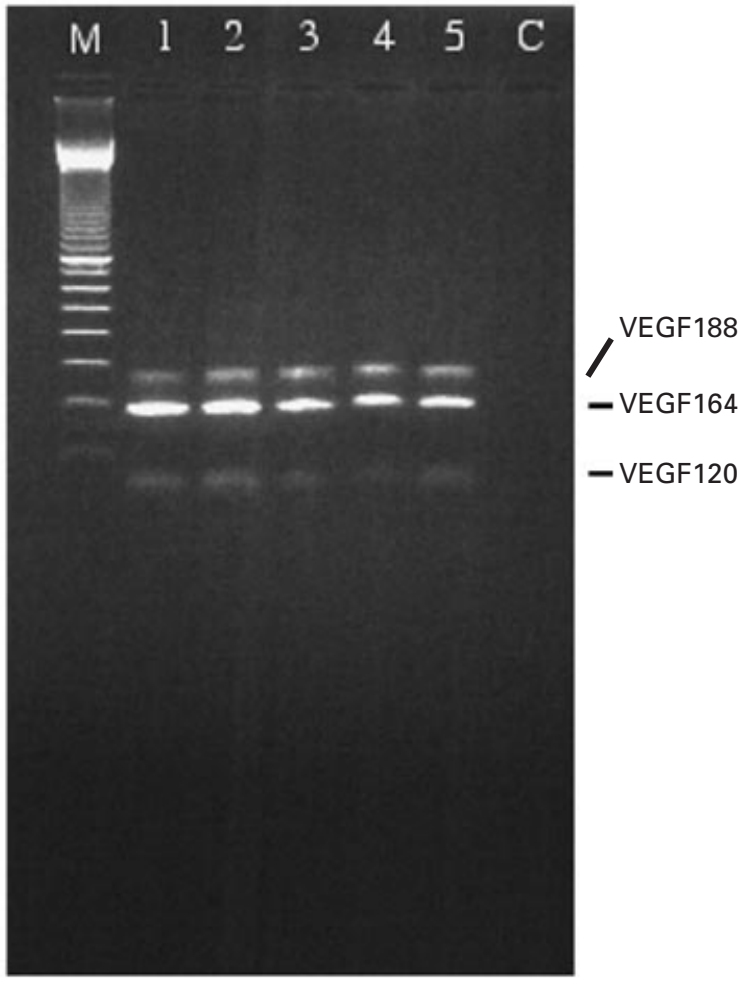

Fig. 1. RT-PCR analysis for vascular endothelial growth factor (VEGF) in pig gestational tissues at different stages of pregnancy. Lanes 1-5: material collected at days 18, 22, 51, 92 and 108 of gestation, respectively. Lane M: 100 base pair ladder molecular mass marker. Lane C: no template control.

Staining of the myometrium was also observed, although at a weaker intensity. In the tissue obtained from animals after day 51 of gestation, indentations in the surface of the epithelia were observed where capillaries were present. In these cases, strong staining for VEGF in the epithelia was observed (Fig. 2d-f). Vascular smooth muscle around some of the larger vessels also stained for VEGF. Immunostaining was also detected in some vessels and may reflect the presence of VEGF bound to its endothelial cell receptors (Fig. 2e, arrow). The negative control sections, in which the primary antibody was replaced with an irrelevant IgG or was pre-adsorbed with excess peptide antigen, showed negligible staining (Fig. 2c and g, respectively).

The localization of VEGF mRNA by in situ hybridization is in agreement with the results obtained by immunocytochemistry. For example, hybridization was observed over both the maternal and fetal epithelial surfaces (Fig. 3b-e). This pattern of hybridization was consistent throughout gestation. However, one difference observed between immunohistochemistry and in situ hybridization results was that the hybridization signal over the maternal glands was generally weak (Fig. 3b), whereas immunohistochemical staining of these cells was strong (Fig. 2a,b). 

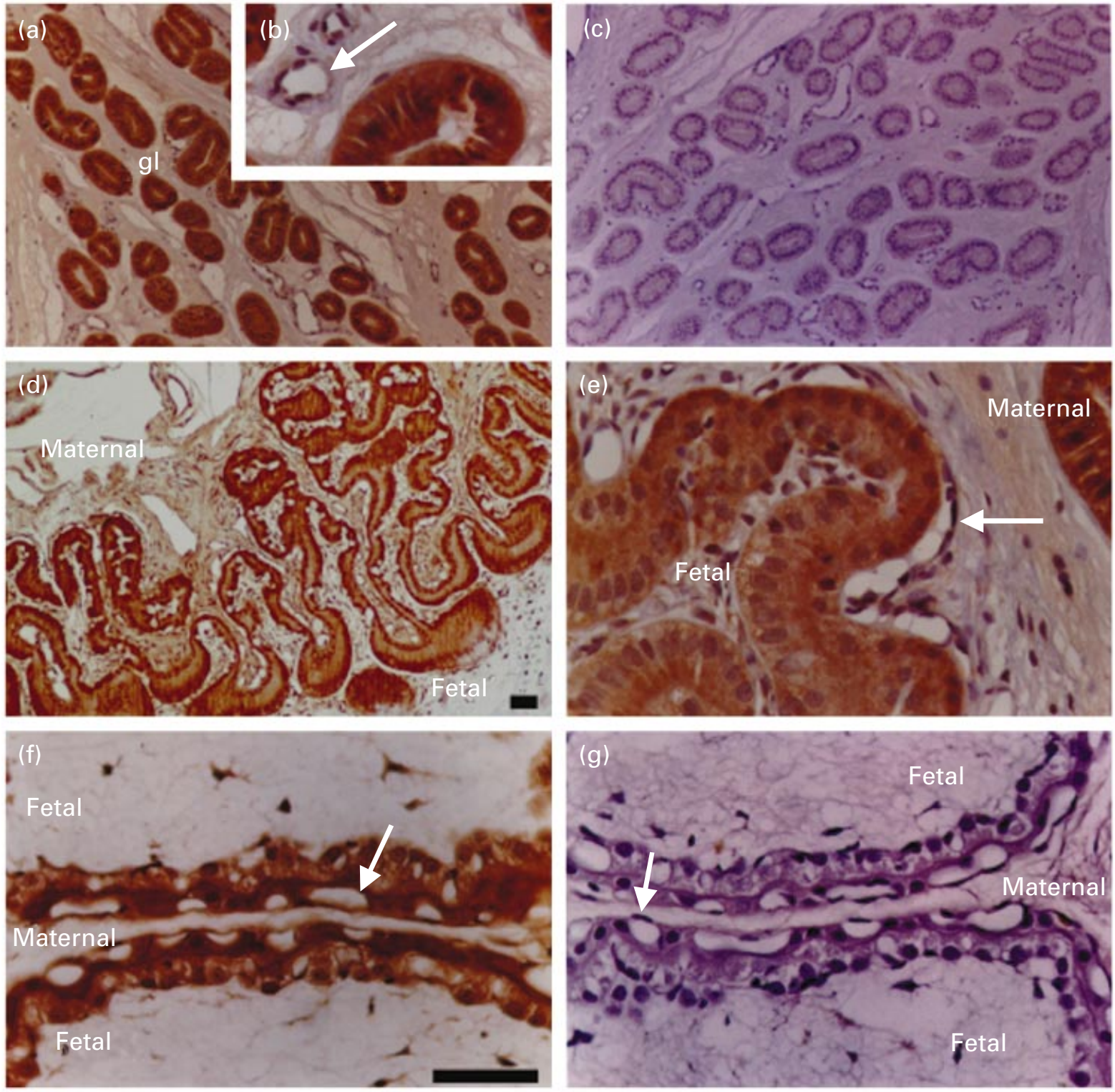

Fig. 2. Immunohistochemistry for vascular endothelial growth factor (VEGF) in pig gestational tissues showing positive staining in $(\mathrm{a}, \mathrm{b})$ maternal glands $(\mathrm{gl})$ and $(\mathrm{d}-\mathrm{f})$ folded epithelial surfaces. Blood vessels can be seen clearly in the perfusion fixed material $(\mathrm{d}-\mathrm{g})$, as indicated by an arrow in (e) and (g). Tissue shown in (a-e) was obtained at day 51 after mating and tissue in ( $\mathrm{f}$ ) and (g) was obtained at day 108 after mating. (c,g) Negative controls stained with non-immune IgG or after preadsorption with excess peptide antigen, respectively. Maternal and fetal compartments are labelled in (d-g). Scale bars represent (a,c,d) $100 \mu \mathrm{m}$ and (b,e,f,g) $50 \mu \mathrm{m}$.

This difference was evident at all time points tested. The in situ hybridization signal appeared to be stronger over cells in the folded epithelial surfaces, although hybridization of stromal cells also occurred (Fig. 3d,e).

\section{I-VEGF binding}

Sections of unfixed frozen tissue were incubated in the presence of [125I]-labelled VEGF. After the sections were washed and fixed, autoradiographic emulsion was used to localize the cellular binding sites for VEGF.
Early in gestation (day 25), when there is little folding of the epithelial surfaces, maternal blood vessels were detected below the layers of epithelia (Fig. 4a, arrow). The binding sites for ${ }^{125}$ I-labelled VEGF were also located below the epithelial surface (Fig. 4b). There was no binding of the 125-labelled VEGF to the maternal glands or stroma at any time, but there was strong binding to the blood vessels (Fig. $4 f, g)$.

Immunostaining (with MIL-11) to localize the endothelial cells around the apposed maternal and fetal epithelial surfaces showed an extremely high density of blood vessels 

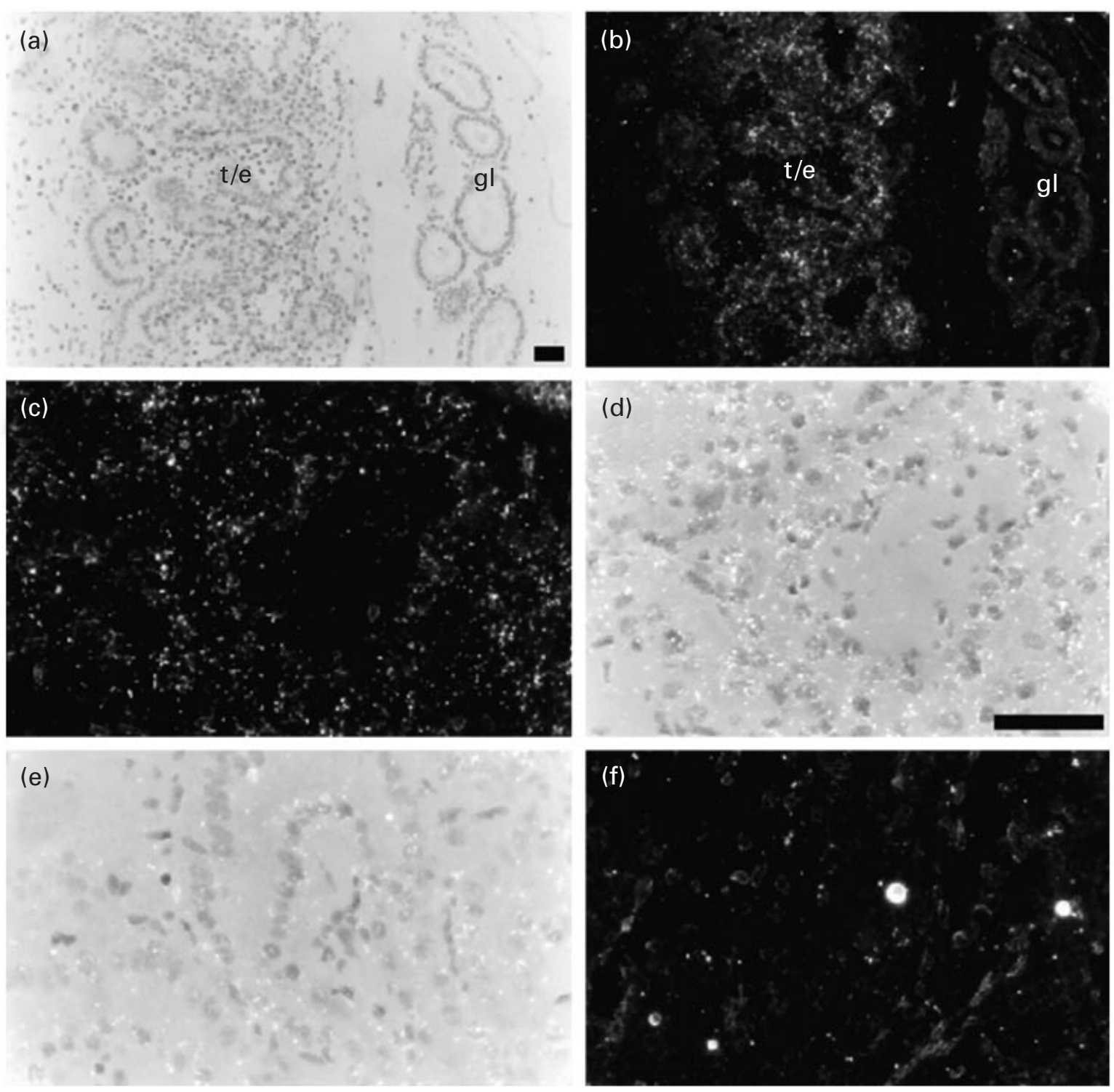

Fig. 3. In situ hybridization for vascular endothelial growth factor (VEGF) in pig gestational tissue with a probe specific, antisense (a-e) and sense control (f). Bright field (a) and dark field (b) images of trophoblast/maternal epithelium (t/e) and glands (gl) obtained at day 92 after mating. Dark field (c) or double exposures (d,e) of trophoblast and epithelium at day 92 after mating $(c, d)$ and at day 51 after mating (e). (f) Dark field view of the sense control on day 51 after mating tissue. Scale bars represent $(\mathrm{a}, \mathrm{b}) 100 \mu \mathrm{m}$ and $(\mathrm{c}-\mathrm{f}) 50 \mu \mathrm{m}$.

in close association with the epithelial cells (Fig. 4c). These vessels were also apparent in the perfusion fixed material (Figs $2 \mathrm{c}-\mathrm{f}$, 4d). This finding was in marked contrast to that in the maternal stroma in which, although there were numerous glands, there were relatively few capillaries (data not shown).

Specific binding sites for VEGF were abundant over the epithelial folds. Ligand binding and immunohistochemistry were carried out on the same tissue sections to determine which cells bound VEGF. Results showed that VEGF bound to the capillary endothelial cells and not to the epithelial cells (Fig. 4e, arrow).

\section{Discussion}

Observations reported in this study confirm that, in pigs, as in other species, VEGF and its receptors in pigs, as in other species, are expressed abundantly in placental tissue. Detection of VEGF RNA by RT-PCR and in situ hybridization indicates that local production of VEGF is possible, and the detection of immunoreactive protein indicates that local production occurs. The RT-PCR results indicate that alternative splicing of the VEGF primary transcript also occurs in the pig placenta. The relative abundance of each of the isoforms is similar to that found in 

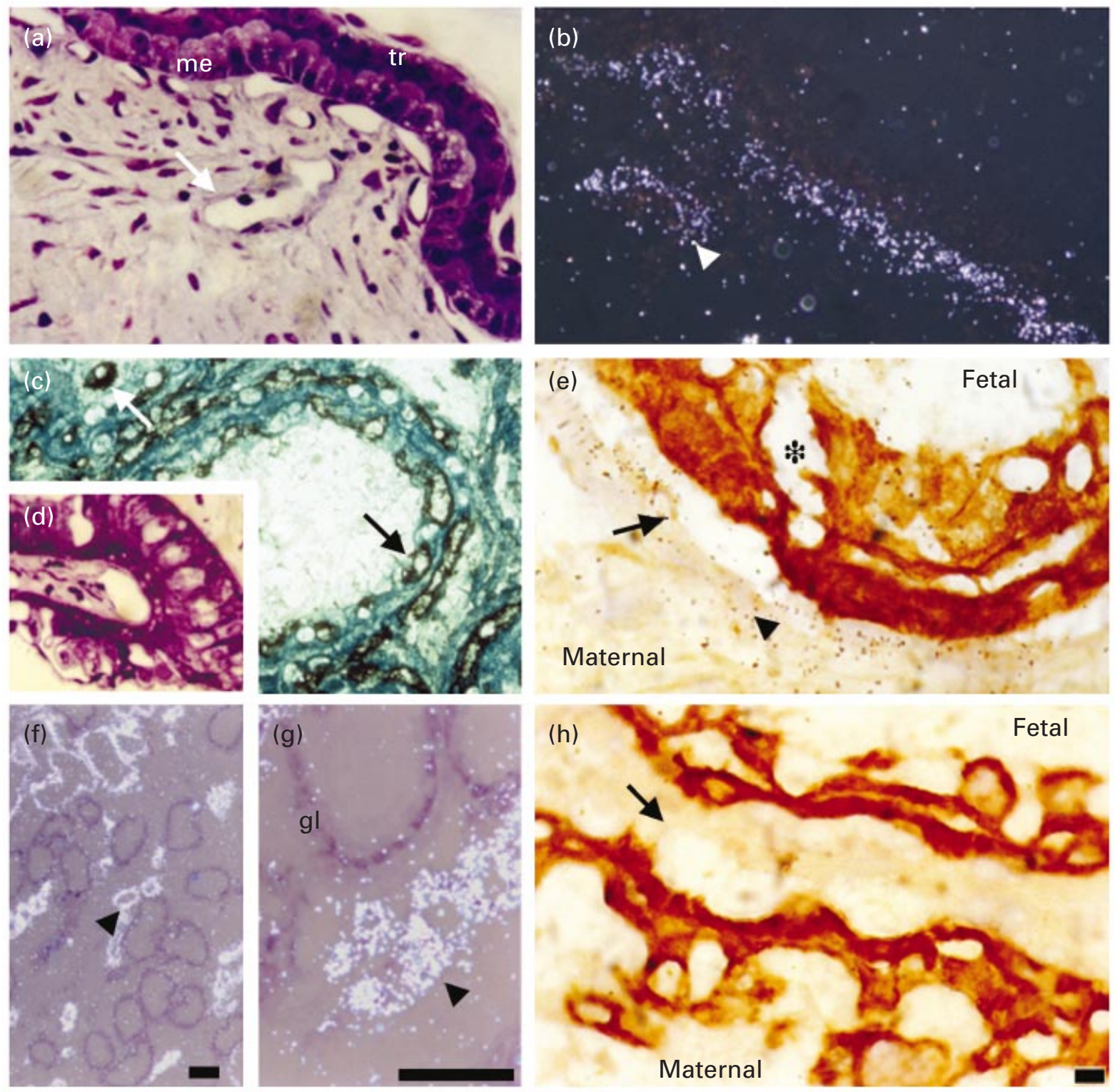

Fig. 4. Binding of ${ }^{125}$ I-labelled vascular endothelial growth factor (VEGF) in pig gestational tissues. (a,d) Perfusion-fixed epithelial surfaces at day 25 and day 100 after mating, respectively, in which blood vessels can be seen clearly. (c) Immunostaining of endothelial cells (black stain) with MIL-11 in tissue obtained at day 51 after mating. (b) Dark field image of ${ }^{125} \mathrm{I}$-labelled VEGF binding on tissue obtained at day 24 after mating which is similar to that shown in (a). (f,g) Bright field and dark field double exposures of ${ }^{125}$ I-labelled VEGF binding to blood vessels but not to maternal glands in material obtained at day 22 after mating. (e,h) Combined immunohistochemistry for cytokeratin (epithelial cells, brown stain) and ${ }^{125}$ I-labelled VEGF binding (silver grains). (h) Negative control for the ligand binding where excess cold VEGF was also added. gl: gland; me: maternal epithelium; tr: trophoblast epithelium; *: freezing damage; arrows indicate blood vessels and arrowheads indicate ${ }^{125}$ I-labelled VEGF binding. Scale bars represent (a,b,c,g) $50 \mu \mathrm{m},(\mathrm{d}, \mathrm{e}, \mathrm{h}) 10 \mu \mathrm{m}$ and (f) $100 \mu \mathrm{m}$.

other species; in humans, sheep and mice a 165 or 164 amino acid form is the most abundant form (Sharkey et al., 1993; Charnock-Jones et al., 1994, Cheung et al., 1995).

The presence of VEGF at the maternofetal interface is consistent with the known functions of this growth factor. VEGF is a potent stimulator of angiogenesis in the chick chorioallantoic membrane (Wilting et al., 1993) and the rabbit cornea vascularization assay (Phillips et al., 1994). As the placenta is one of the few sites in the adult animal in which there is marked and prolonged angiogenesis, the presence of a potent stimulator of angiogenesis, such as VEGF, in the placenta is not unexpected. VEGF has also been isolated and identified as a vascular permeability factor (VPF) (Keck et al., 1989), and this study showed that VEGF/VPF was an extremely potent stimulator of vascular permeability. This role may be significant in the placenta as 
the release of substances from the capillaries on either side of the maternofetal interface could have a direct effect on transport across the interface.

In situ hybridization studies using a human VEGF probe indicated that the major site of VEGF expression was the epithelial interface, which separates the maternal and fetal compartments. Hybridization over other types of cell, such as the maternal glands, was generally much weaker. Similarly, localization of immunoreactive protein indicated that the maternal and fetal epithelial surfaces contain abundant VEGF. However, staining was also observed over the maternal glands and scattered cells within the maternal stroma when this technique was used. This apparent discrepancy may be due to the differential sensitivity of the two techniques. It is unlikely that the immunostaining is the result of non-specific binding as control sections, in which the primary antibody was either replaced with an irrelevant IgG or was pre-absorbed with an excess of the peptide to which the antiserum was raised, showed no staining over either glands or epithelial cells.

In the perfusion-fixed placental tissues, the capillaries that indent the epithelial surfaces during the last two-thirds of gestation were evident. The endothelial cells that line these capillaries did not stain with the VEGF antiserum, whereas there was strong staining of neighbouring epithelial cells. This finding indicates that VEGF produced by the epithelial cells acts directly in a paracrine fashion on the endothelial cells of these capillaries. It is also possible that VEGF produced by the epithelial cells stimulates the growth and development of the complex subepithelial capillary bed that is present in these tissues (Dantzer and Leiser, 1994; Leiser and Dantzer, 1994). Production of VEGF by the epithelial cells would also favour the development of the close relationship between the epithelial and endothelial cells seen at the maternofetal interface.

For placental VEGF to have a local effect, the appropriate high affinity receptors would have to be present on the surface of the target cells. Numerous studies have demonstrated that two high affinity receptors (flt- 1 and KDR; Shibuya et al., 1990, Terman et al., 1992) are localized on capillary endothelial cells. Other studies have demonstrated direct actions of VEGF on macrophages and monocytes (Clauss et al., 1990, McLaren et al., 1996). In the present study, ligand binding studies were undertaken using ${ }^{125}$-labelled VEGF to identify VEGF receptors. This technique demonstrated the presence of VEGF binding sites on both fetal and maternal capillaries in the pig placenta. However, because this technique necessitates the use of unfixed frozen sections, the tissue preservation is poor. Furthermore, the autoradiographic resolution of this technique is low as the autoradiographic label $\left({ }^{125} \mathrm{I}\right)$ is a high energy gamma emitter. Therefore, it was not possible to resolve the very small capillaries that are in close apposition to the fetal and maternal epithelial surfaces. An attempt was made to address this problem by performing ligand binding and immunohistochemistry on the same slide. The anti-cytokeratin antibody identified the trophoblast and maternal epithelial cells; the silver grains did not overlay these cells. Thus, the VEGF binding sites are not present on the trophoblast cells, but are located on the capillaries. Immunohistochemistry has been used to confirm the localization of VEGF receptors; however, using anti-VEGF receptor antibodies (Santa Cruz Biotechology Inc.) that are currently available, it has not been possible to obtain specific reproducible staining in this tissue (D. S. Charnock-Jones and D. Licence, unpublished).

In previous studies, in situ hybridization revealed that the human trophoblast contains mRNA encoding at least a portion of a VEGF receptor (Charnock-Jones et al., 1994). The human trophoblast-like cell line BeWo was able to respond by specific time- and dose-dependent phosphorylation of a variety of proteins when stimulated with VEGF. It was suggested that VEGF may have direct actions on invasive trophoblast and, therefore, it was of interest to determine whether expression of VEGF receptors occurs on non-invasive trophoblast such as that found in pigs. However, subsequently, Clark et al. (1998) reported that there are no VEGF binding sites on human villus placental cells and that the mRNA originally detected by in situ hybridization encodes a soluble form of the VEGF receptor. The data presented in the present study showing that the VEGF binding sites are confined to the endothelial cells indicates that, as in human trophoblast, pig trophoblast is unlikely to respond directly to VEGF. However, there is an extremely close relationship between the capillaries that indent deeply into the epithelial cells that form the maternofetal interface. This close relationship reduces the distance of diffusion between the maternal and fetal circulations. VEGF produced by the epithelial cells (both fetal and maternal) is likely to be essential in stimulating the development of the deeply indented dense capillary network at this site.

The data presented in the present study show that VEGF is produced in placental tissue of pigs, and that target cells are also present in this tissue. The data also indicate that VEGF acts in a paracrine manner and may carry out one or more roles. For example, VEGF may stimulate the growth of, and attract the capillaries to, the epithelial surface; it may stimulate the continued growth of blood vessels throughout gestation, increasing the surface area and, therefore, the exchange capacity of the placenta; and it may be involved in stimulating or regulating the permeability of the endothelial cells. Furthermore, the ligand binding experiments indicate that binding sites for VEGF are limited to endothelial cells.

D. E. Clark was supported by an MRC project grant: G9331232PA. D. S. Charnock-Jones was supported by BBSRC (Fellowship No. PDF/22).

\section{References}

Alon T, Hemo I, Itin A, Pe'er J, Stone J and Keshet E (1995) Vascular endothelial growth factor acts as a survival factor for newly formed retinal vessels and has implications for retinopathy of prematurity Nature Medicine 1 1024-1028 
Anthony FW, Wheeler T, Elcock CL, Pickett M and Thomas EJ (1994) Identification of a specific pattern of vascular endothelial growth factor mRNA expression in human placenta and cultured placental fibroblasts Placenta 15 557-561

Berse B, Brown LF, Van de Water L, Dvorak HF and Senger DR (1992) Vascular permeability factor (vascular endothelial growth factor) gene is expressed differentially in normal tissues, macrophages and tumors Molecular Biology of the Cell 3 211-220

Carmeliet P, Ferreira V, Breier G et al. (1996) Abnormal blood vessel development and lethality in embryos lacking a single VEGF allele Nature 380 435-439

Charnock-Jones DS, Sharkey AM, Rajput-Williams J, Burch D, Schofield JP, Fountain SA, Boocock CA and Smith SK (1993) Identification and localization of alternately spliced mRNAs for vascular endothelial growth factor in human uterus and estradiol regulation in endometrial carcinoma cell lines Biology of Reproduction 48 1120-1128

Charnock-Jones DS, Sharkey AM, Boocock CA, Ahmed A, Plevin R, Ferrara N and Smith SK (1994) Vascular endothelial growth factor receptor localization and activation in human trophoblast and choriocarcinoma cells Biology of Reproduction 51 524-530

Cheung CY, Singh M, Ebaugh MJ and Brace RA (1995) Vascular endothelial growth factor gene expression in ovine placenta and fetal membranes American Journal of Obstetrics and Gynecology 173 753-759

Clark DE, Smith SK, Sharkey AM and Charnock-Jones DS (1996) Localisation of VEGF and expression of its receptors flt and KDR in human placenta throughout pregnancy Human Reproduction 11 1090-1098

Clark DE, Smith SK, He Y, Day KE, Licence DR and Charnock-Jones DS (1998) A vascular endothelial growth factor antagonist is produced by the placenta and released into the maternal circulation Biology of Reproduction 59 1540-1548

Clauss M, Gerlach M, Gerlach H et al. (1990) Vascular permeability factor: a tumour-derived polypeptide that induces endothelial cell and monocyte procoagulant activity, and promotes monocyte migration Journal of Experimental Medicine 172 1535-1545

Dantzer V and Leiser R (1994) Initial vascularisation of the pig placenta: 1. Demonstration of non-glandular areas by histology and corrosion casts Anatomical Record 238 177-190

Ferrara N, Carver-Moore K, Chen H, Dowd M, Lu L, O'Shea KS, PowellBraxton L, Hillan KJ and Moore MW (1996) Heterozygous embryonic lethality induced by targeted inactivation of the VEGF gene Nature $\mathbf{3 8 0}$ 439-442

Gadsby JE, Heap RB and Burton RD (1980) Oestrogen production of blastocyst and early embryonic tissue of various species Journal of Reproduction and Fertility $60409-417$

Hanahan D and Folkman J (1996) Patterns and emerging mechanisms of the angiogenic switch during tumorigenesis Cell 86 353-364

Houck KA, Ferrara N, Winer J, Cachianes G, Li B and Leung DW (1991) The vascular endothelial growth factor family: identification of a fourth molecular species and characterization of alternative splicing of RNA Molecular Endocrinology 5 1806-1814

Jackson MR, Carney EW, Lye SJ and Knox Ritchie JW (1994) Localization of two angiogenic growth factors (PDECGF and VEGF) in human placentae throughout gestation Placenta $15341-353$

Jakeman LB, Armanini M, Phillips HS and Ferrara N (1993) Developmental expression of binding sites and messenger ribonucleic acid for vascular endothelial growth factor suggests a role for this protein in vasculogenesis and angiogenesis Endocrinology 133 848-859

Keck PJ, Hauser SD, Krivig Sanzo K, Warren T, Feder J and Connolly DT (1989) Vascular permeability factor, an endothelial cell mitogen related to PDGF Science 246 1309-1312

Leiser R and Dantzer V (1994) Initial vascularisation of the pig placenta: 2 Demonstration of gland and areola-gland sub-units by histology and corrosion casts Anatomical Record 238 326-334

Leung DW, Cachianes G, Kuang W-J, Goeddel DV and Ferrara N (1989) Vascular endothelial growth factor is a secreated angiogenic mitogen Science 246 1306-1309

McLaren J, Prentice A, Charnock-Jones DS, Sharkey A, Millican S and Smith SK (1996) In situ hybridization and immunocytochemical localization of vascular endothelial growth factor in ectopic endometrial tissue and activated peritoneal macrophages Journal of Clinical Investigation 98 482-489

Phillips GD, Stone AM, Jones BD, Schultz JC, Whitehead RA and Knighton DR (1994) Vascular endothelial growth factor (rhVEGF165) stimulates direct angiogenesis in the rabbit cornea In Vivo 8 961-965

Phillips HS, Hains J, Leung DW and Ferrara N (1990) Vascular endothelial growth factor is expressed in rat corpus luteum Endocrinology 127 965-967

Sharaishi S, Nakagawa K, Kinukawa N, Nakano H and Sueishi K (1996) Immunohistochemical localisation of vascular endothelial growth factor in the human placenta Placenta 17 111-121

Sharkey AM, Charnock-Jones DS, Boocock CA, Brown KD and Smith SK (1993) Expression of mRNA for vascular endothelial growth factor in human placenta Journal of Reproduction and Fertility 99 609-615

Shibuya M, Yamaaguchi S, Yamane A, Ikeda T, Tojo A, Matsushime H and Sato $\mathbf{M}$ (1990) Nucleotide sequence and expression of a novel human receptor-type tyrosine kinase gene (flt) closely related to the fms family Oncogene 5 519-524

Shweiki D, Itin A, Newfeld G, Gitay-Goren H and Keshet E (1993) Patterns of expression of vascular endothelial growth factor (VEGF) and VEGF receptors in mice suggest a role in hormonally regulated angiogenesis Journal of Clinical Investigation 91 2235-2243

Terman BI, Dougher-Vermazen M, Carrion ME, Dimitrov D, Armellino DC, Gospodarowicz D and Bohlen P (1992) Identification of the KDR tyrosine kinase as a receptor for vascular endothelial cell growth factor Biochemical and Biophysical Research Communications 187 1579-1586

Torry DS, Holt VJ, Keenan JA, Harris G, Caudle MR and Torry RJ (1996) Vascular endothelial growth factor expression in cycling human endometrium Fertility and Sterility 66 72-80

Wilting J, Christ B, Bokeloh M and Weich HA (1993) In vivo effects of vascular endothelial growth factor on the chicken chorioallantoic membrane Cell and Tissue Research 274 163-172

Wooding FBP and Flint APF (1994) Placentation. In Marshall's Physiology of Reproduction 4th Edn. pp 233-460 Ed. E Lamming. Chapman \& Hall, London

Manuscript received 19 May 1999.

First decision 12 August 1999.

Revised version received 11 April 2001.

Accepted 25 June 2001. 